\title{
ASSOCIAÇÃO BRASILEIRA DE ENFERMAGEM: 70 anos de luta pela vida. ${ }^{1}$
}

\author{
BRAZILIAN NURSING ASSOCIATION: 70 YEARS OF STRUGGLE FOR LIFE.
}

\author{
Ana Kelve de Castro Rodrigues ${ }^{2}$ \\ Cristianne Soares Chaves ${ }^{3}$ \\ Thereza Maria Magalhães Moreira ${ }^{3}$ \\ Zulene Maria de Vasconcelos Varela ${ }^{4}$
}

\begin{abstract}
RESUMO: Relata-se a origem, organização, expansão, projeção da Associação Brasileira de Enfermagem (ABEn), associadas à sua filosofia e pondo em evidência suas realizações, desde sua origem, em 1926, até o momento atual, em que se comemora seus 70 anos. O principal objetivo do trabalho foi relatar a história da entidade ao longo dos seus 70 anos e narrar o incentivo propiciado pela mesma para que a enfermagem contribua decididamente para a construção de um corpo de conhecimentos próprios da profissão, a definição legal do exercício da profissão, a regulamentação do ensino através de suas comissões. A metodologia foi composta de pesquisa bibliográfica e entrevista com profissionais atuantes. Conclui-se que a ABEn está cada vez mais forte e consciente de como fazer para alcançar muitos outros objetivos para originar grandes conquistas que contribuirão para garantir o espaço e o poder da enfermagem como profissão voltada para o ser humano, portanto, para uma vida melhor, com mais amor, paz e justiça social.
\end{abstract}

UNITERMOS: Entidade de classe - Histórico - Desempenho institucional - Lutas e conquistas.

\begin{abstract}
This work is about the Brazilian Nursing Association (ABEn), its origin, its expansion and projection based on its philosophy and highlighting its achievements from its origin in 1926 until today when its $70^{\text {th }}$ anniversary is being celebrated. This work aims at reporting this institution history and narrating the support provided so that nursing may contribute decisively to the construction of a body of profession knowledge itself, the legal definition of professional practice, teaching regulamentation through its commissions. Methodology has been composed of bibliographic research and interviews with active professionals. It has been concluded that $A B E n$ is stronger and stronger and aware of the way on how to achieve many other goals which will bear great conquests which will contribute for granting nursing power and space as a profession set to the human, therefore, to a better life, with more love, peace and social justice.
\end{abstract}

KEYWORDS: Class entity - Historical - Institutional performance - Fights and conquests.

\footnotetext{
${ }^{1}$ Trabalho apresentado no $48^{\circ}$ CBEn. - São Paulo - SP, outubro de 1996.

${ }^{2}$ Acadêmica do $7^{\circ}$ semestre. de enfermagem da UFC/bolsista do PET.

${ }^{3}$ Acadèmicas do $8^{\circ}$ semestre de enfermagem da UFC/ bolsistas do PET.

${ }^{4}$ Professora Titular do DENF/CCS/UFC - Tutora do PET.
} 


\section{INTRODUÇÃO}

Caracteriza-se a Associação Brasileira de Enfermagem(ABEn) como sendo uma entidade civil, sem fins lucrativos e de caráter sócio-cultural que reúne enfermeiros, técnicos e acadêmicos de enfermagem. Foi fundada em 12 de agosto de 1926 com o nome de Associação Nacional de Enfermeiras Diplomadas'.

É uma entidade presente no cotidiano técnico-cultural, científico e político do país, atuando através de meios veiculadores de informações e conhecimento entre os profissionais de enfermagem, sendo alguns destes meios: a Revista Brasileira de Enfermagem-REBEn, o Informativo ABEn, o Congresso Brasileiro de Enfermagem, a Semana Brasileira de Enfermagem, os Encontros Regionais, - Seminário Nacional de Pesquisa, os Comitês de ensino de graduação e pósgraduação e o Jornal Brasileiro de Enfermagem. Comemorou, em 1996, 70 anos de criação, motivo pelo qual foi escolhido o "slogan" Muitas Lutas, Muitas Conquistas, Uma Causa: a vida para tema do $48^{\circ}$ Congresso Brasileiro de Enfermagem e $57^{\text {a }}$ Semana Brasileira de Enfermagem.

Apesar de tamanha atuação, não há um reconhecimento total da categoria em relação à existência da associação e seu papel dentro da formação do profissional de enfermagem. Diante dessa problemática, tem-se como objetivo geral: Relatar a história da Associação Brasileira de Enfermagem ao longo dos seus 70 anos, ressaltando suas lutas e conquistas. E como objetivos específicos: Descrever marcos históricos e conceituais no decorrer dos 70 anos da ABEn; Apresentar, centrados na filosofia da ABEn, seus princípios e finalidades e Ressaltar o valor histórico dessa associação para a referida profissão.

\section{METODOLOGIA}

A estruturação deste trabalho deu-se a partir de análise documental (Revista Brasileira de Enfermagem, Anais, Informativo e trabalhos publicados) e de entrevista semi - estruturada com enfermeiras de reconhecida atuação dentro da enfermagem cearense, com manifestada ação junto à ABEn. Estes depoimentos foram referentes aos últimos dez anos.

Realizou-se visitas à sede da $A B E n$ - $C E$, visando o conhecimento acerca do funcionamento dessa e dos paradigmas que regem a sua atuação nos diversos niveis.

\section{ANTECEDENTES HISTÓRICOS}

A Associação Brasileira de Enfermagem(ABEn) tem sua origem estreitamente ligada à Escola de Enfermagem Ana Nery da Universidade Federal do Rio de Janeiro (à época Universidade do Brasil). A referida Escola foi criada em 1922 e regulamentada em 1923 em regime de subordinação ao serviço de enfermeiras do Departamento Nacional de Saúde Pública (DNSP) e do então Ministério da Justiça e Negócios Interiores. 
Para melhor compreensão de sua origem, caracterizamos o Brasil da década de 20, dando mais enfoque ao Rio de Janeiro, então capital brasileira, cuja população era de 1.157 .873 habitantes $(3,78 \%$ do total, dos quais $38 \%$ eram iletrados). O sistema educacional do país procurava dar, pelo menos, instrução primária a uma parte da população, sendo que o preparo profissional ficava restrito à elite que freqüentava escolas particulares. Mas, dentro da estrutura familiar, os homens tinham prioridade em seguir uma carreira universitária, enquanto que às mulheres era reservada, apenas, uma "boa formação para o lar". Apesar de esta ser uma situação aceita pela sociedade da época, o movimento feminista liderado por Bertha Lutz já demonstrava uma certa mudança do pensamento feminino e propunha uma modificação da posição da mulher dentro da sociedade. ${ }^{1}$

À época, a cidade do Rio de Janeiro encontrava-se frente a uma realidade preocupante devido às más condições de saúde da população. Isto incentivou o preparo de pessoal especializado no cuidado com os doentes, já iniciado desde 1890, quando se oficializou o ensino de enfermagem no Brasil (nos moldes da Escola Francesa de Salpetrière e visando preparar, em dois anos, enfermeiras para trabalhar nos hospícios e hospitais civis e militares). Cursos foram surgindo com o propósito de suprir as necessidades básicas existentes, bem como capacitar pessoal para tais atividades. Foi criada, em março de 1916, a Escola Prática de Enfermagem da Cruz Vermelha Brasileira, filial do Rio de Janeiro, que oferecia cursos de um ano a princípio e, em 1917, de dois anos.

Com a reorganização da saúde pública (no Rio de Janeiro, em 1920) e as constantes viagens de estudos de médicos brasileiros à Europa e aos Estados Unidos da América do Norte, emergiu uma nova concepção sobre o papel que a enfermeira poderia desempenhar na saúde comunitária. Naquela época, o Departamento Nacional de Saúde Pública (DNSP) encontrava-se em grande desenvolvimento e seu diretor, Carlos Chagas, após uma viagem aos Estados Unidos, teve uma compreensão mais ampla da potencialidade do serviço de enfermagem e solicitou o apoio da Fundação Rockfeller para a organização, no Brasil, de um serviço de enfermeiras de saúde pública.

Com essa finalidade, chega ao Brasil, em 1921, Ethel O. Parsons, da Fundação Rockfeller, que chefiou a missão técnica de cooperação para o desenvolvimento da enfermagem no Brasil. Foram criados, em 1922, o Serviço de Enfermeiras do DNSP(com o mesmo nivel de autoridade dos demais serviços do Departamento) e a Escola de Enfermeiras (com a finalidade de preparar pessoal especializado de enfermagem para atuar sobre os problemas de saúde brasileiros, conforme Decreto $N^{\circ} 15.799$, de 10/11/1922). Com a aprovação do regulamento do código sanitário de Carlos Chagas no DNSP(Decreto № 16.300, de 31/12/1923), foi regulamentada a Escola de Enfermeiras do DNSP. 
O Brasil contou com a contribuição das enfermeiras da missão técnica advindas da América do Norte e da Europa, que exerceram função na saúde pública e na Escola de Enfermeiras no periodo de 1921 a 1931. Alguns nomes merecem ser lembrados:

- Ethel Parsons ocupou o cargo de superintendente geral do serviço de enfermeiras e fez passar a todos que a enfermagem como profissão se fortalece de nobreza, dignidade, responsabilidade e ética, incentivando as mulheres brasileiras a entrar na Escola de Enfermagem e ajudando a criar a Associação Brasileira de Enfermeiras Diplomadas.

- Edith de Magalhães Fraenkel, cedo, no Brasil, fez o curso de enfermagem de guerra na Cruz Vermelha e, posteriormente com auxílio da Fundação Rockfeller, viajou para o EUA, lá fazendo o curso completo. Voltou ao Brasil onde esteve como instrutora na Escola de Enfermagem, tendo assumido de 1931 a 1940 a Superintendência Geral do Serviço de Enfermeiros do DNSP, sendo a segunda e última a fazêlo. Ao sair da superintendência, ficou em disponibilidade junto ao governo do Estado de São Paulo para organizar o que viria a ser a Escola de Enfermagem da Universidade de São Paulo. Retrataram-na como pessoa enérgica, que sabia agir nas mais variadas situações de enfermagem, inclusive em emergências.

- Lilian Clayton era mais voltada para a prestação de cuidados aos pacientes e para a formação de enfermeiros, mas dava grande ênfase às idéias de uma associação e de uma revista para a categoria.

- Clara Louise Kieninger (primeira diretora da Escola Ana Neri atuando entre fevereiro de 1923 e julho de 1925) instituiu a Associação do Governo Interno das Alunas, base para a posterior organização da Associação das Egressas e Pré-concludentes, que em um período mais tardio passou a se chamar de Associação Brasileira de Enfermagem. Sob sua orientação ocorreu também a formação do Conselho dos Estudantes. Os alunos participantes destes criaram, em 1926, a Associação Nacional de Enfermeiras Diplomadas.

- Bertha Lucile Pullen (terceira diretora da Escola Ana Neri) fez, em 1931, um esboço de estudo para a incorporação da escola à Universidade do Brasil, atual UFRJ. Foi importante incentivadora da associação de classe.

- Rachel Haddock Lobo fez os quatro últimos meses do curso de enfermagem de saúde pública no Brasil. Em 1925 passou à supervisão do serviço de saúde pública. Sua contribuição para o ensino da enfermagem deu-se através de seu trabalho na Escola de Enfermagem Ana Neri. Foi responsável pela fundação da Revista Anais de Enfermagem, participou da Associação Nacional de Enfermeiras diplomadas, Associação para o Progresso da Mulher e outros, marcando sua trajetória. 
A Escola de Enfermagem Ana Neri passou por diversas fases e conseqüentes designações durante seu periodo de formação. Pelo Decreto $\mathbf{N}^{\circ}$ 17268, de 1926, a Escola de Enfermeiros do Departamento Nacional de Saúde Pública denominou-se de Escola de Enfermagem Dona Ana Neri. E, através do Decreto $N^{\circ}$ 20109131, designou-se Escola de Enfermeiras Ana Neri, incorporando-se à Universidade do Brasil como instituto de ensino complementar. Somente com o Decreto 21.321, de 1946, a Escola foi integrada à mesma Universidade como estabelecimento de ensino superior.

\section{DESPERTAR DE UMA LUTA}

Dentre as treze graduadas da primeira turma da Escola de Enfermeiras Ana Neri, em 1925, cinco ganharam bolsa de estudo nos EUA, enquanto que as demais permaneceram no Rio de Janeiro. Tendo a filosofia da Associação do Governo Interno das Alunas presente em seus pensamentos, deram um passo importante para estruturação de uma futura associação onde compartilhassem e discutissem sobre problemas existentes, buscando soluções com o intuito de formar seu estatuto e sindicato de classe.

Com o fim do contrato de prestação de serviço ao DNSP em dezembro do mesmo ano, o grupo que se manteve no Brasil retorna à Escola Ana Neri e fica por dois meses. Essa volta possibilitou a integração freqüente entre as egressas e pré-concludentes, levando à retomada da idéia de formar uma associação de ex-alunas que reunisse as diplomadas da Escola D. Ana Neri. Este pensamento tomou corpo a partir da ânsia de luta por melhores condições de trabalho e passou a existir através da união das turmas de diplomadas e préconcludentes, contando com o apoio de Edith Fraenkel, Ethel O. Parsons e pela diretora da Escola Ana Neri, que formaram a Associação Nacional de Enfermeiras Diplomadas- ANED.

O pensamento inicial do grupo foi o de elaborar um estatuto sob a supervisão da diretoria da ANED. A minuta do estatuto foi feita e sua leitura realizada no dia 12 de agosto de 1926, data que marca o início da ABEn. Em 1929, a ANED teve o seu nome modificado para ANEDB (Associação Nacional Enfermeiras Diplomadas Brasileiras), por exigência do $I C N^{1}$. Segundo este, as associações deveriam identificar-se de acordo com sua nacionalidade para participar de um congresso em Genebra. Ser filiada a uma entidade internacional constituiu-se marco importante na trajetória de lutas e conquistas da ABEn. Permanecer filiada também é motivo justificado de orgulho, como é o caso da ABEn-Brasil.

A ANEDB, somente em 1929, teve sua denominação oficialmente registrada, permanecendo assim até 1944 quando Zaíra Cintra Vidal, avaliando a restruturação da associação, através de novo ${ }^{4}$ estatuto e apoio da classe, passou a chamá-la de ABED (Associação Brasileira de Enfermeiras Diplomadas), permanecendo com essa denominação até o ano de 1954,

\footnotetext{
${ }^{4}$ Sigla em inglês do Conselho Internacional de Enfermagem(International Council of Nursing).
} 
quando, por ocorrência do $7^{\circ}$ Congresso Nacional de Enfermagem, duas ementas importantes foram aprovadas, uma das quais modificava a denominação da entidade para ABEn ( Associação Brasileira de Enfermagem), permanecendo assim até os dias atuais. A segunda foi a criação do órgão oficial de comunicação da ABEn, em 1955, a Revista Brasileira de Enfermagem (REBEn), antes chamada de Revista Anais de Enfermagem em 1932. Nessa época a presidente da associação era a enfermeira Glete de Alcântara, que implementou também o mandato de quatro anos para a diretoria, a inclusão de membros honorários, os congressos bienais e a votação por delegação. A REBEN é outro dos marcos que se deve considerar uma conquista e luta diárias da entidade já que é periódico indexado internacionalmente e permanece até hoje.

Inúmeros problemas foram enfrentados pela associação, tais como: número limitado de associados, sobrecarga de trabalho causada por surtos de variola, febres amarela e tifóide que exigiam freqüentes deslocamentos das enfermeiras de saúde pública para hospitais distantes, etc.

É perceptivel o enorme esforço despendido pelas pioneiras da enfermagem que demonstraram imensa garra e união nas lutas e conquistas ocorridas e que tiveram sempre presente o objetivo de criar condições cada vez mais favoráveis ao desenvolvimento da enfermagem, propiciando, desta maneira, melhores condições de saúde à população. Esta percepção é confirmada pela definição das funções da $A B E n$, que inclui desenvolvimento técnico-científico e cultural na enfermagem através da promoção de congressos, seminários, jornadas e conferências, da relação com organizações e instituições internacionais. Com a fundação da $A B E n$ tem-se uma nova fase na enfermagem, pois a profissão deixa de ser vista, no Brasil, como prática e passa a assumir o caráter científico, o que muito contribui para o seu desenvolvimento técnico-científico. Concretizam-se, desse modo, muitas lutas e conquistas que fortalecem a profissão pela enorme vontade de manter a busca por melhores condições de trabalho para uma enfermagem mais fortalecida.

\section{EXPANSÃo E PROJEÇÃo dA ABEN NO CENÁRIO NACIONAL E INTERNACIONAL}

Este seguimento do trabalho objetiva tornar públicas as realizações e marcos históricos da ABEn, reunindo os acontecimentos do período de 1926 a 1986, os quais fortaleceram suas bases de unificação, deixando evidentes sua importante e necessária atuação como associação de classe.

Um importante veículo de comunicação com circulação nacional e indexada internacionalmente é a Revista de origem brasileira, citada anteriormente como um dos marcos de conquista. Durante estes 64 anos de existência, a Revista tem sido usada como meio de divulgação das realizações das enfermeiras e, não menos, como fonte de pesquisa e atualização sobre assuntos de interesse coletivo, gerando análises e discussões que contribuem para a essência da enfermagem. 
Em alteração do estatuto, realizada pela presidente da ANEDB, Zaíra Cintra Vidal, em 09 de maio de 1944, foram introduzidas e/ou alteradas as seguintes resoluções: mudança de ANEDB para ABED, instituição de defesa jurídica e assistência aos sócios em caso de doença e determinação da construção de colônia de férias. No estatuto atual isto foi abolido.

A partir de 1945 a ABEn começou a disseminar suas sementes, dando novos frutos através da implantação das seções estaduais. Novos capítulos foram introduzidos no estatuto, os quais tratavam das seções estaduais $e$ declaravam que a ABED deveria promover conferências e congressos.

A realização do primeiro Congresso Nacional de Enfermagem deu-se no ano de 1945 na cidade de São Paulo, abordando questões como saúde publica, preparo de enfermeiras chefes e auxiliares de enfermagem e outras. Os Congressos Nacionais da ABEn passaram a ser o fórum de debates, de definições e de resoluções para a categoria. Um fato muito significativo ocorreu nesse evento: foi feita solicitação da criação do Conselho Federal de Enfermagem (COFEN) ao Ex.mo. Sr. Ministro da Educação e Saúde. Essa luta começou em 1945 e a conquista se deu em 1973.

Conta-se até hoje (1996) com a realização de quarenta e sete Congressos Brasileiros de Enfermagem, todos orientados para a busca do desenvolvimento da enfermagem. O congresso comemorativo das Bodas de ouro da ABEn deu-se no Rio de Janeiro, o comemorativo dos 60 anos realizou-se na cidade do Rio de Janeiro e o dos 70 anos realizar-se-á em São Paulo.

Um novo artigo foi introduzido no Estatuto da Associação com objetivo de cumprir a exigência do Ministério da Justiça: para ser considerada como entidade de utilidade pública, a ABEn deveria fazer constar, em seu Estatuto, que os cargos da diretoria e conselho fiscal não eram remunerados, tendo isto ocorrido em 1952. Encaminhou-se à comissão de estatuto por meio da presidente da ABED, Glete de Alcântara (1953) as seguintes propostas: 1.Mandato de quatro anos para a diretoria; 2 .Inclusão de membros honorários; 3.Congressos bienais; 4.Mudança do nome da revista; 5 . Mudança do nome da ABED; 6. Votação por delegação. E, durante o VII Congresso Nacional de Enfermagem, a nova denominação de ABEn e REBEn passaram a vigorar. Ficando claro que só é enfermeiro quem tem diploma oficial.

Tem-se evidência do crescimento e força da ABEn, quando analisamos o que se segue. Iniciou-se com cerca de cinqüenta pessoas e em 29 anos já estava filiada a duas associações internacionais de enfermagem, uma em 1929 que foi - ICN, que tem como objetivo incentivar a criação e o desenvolvimento de associações nacionais, como uma forma para engrandecer a profissão. Através da participação da $\mathrm{ABEn}$ nos inúmeros congressos da ICN, as enfermeiras brasileiras tiveram e têm a oportunidade de mostrar, em meio aos diversos países membros, sua cultura e conhecimento e manter-se atualizadas quanto às conjunturas e cenários internacionais importantes para o desenvolvimento da profissão "pari-passu" com o desenvolvimento mundial. 
Evidência do excelente desempenho do Brasil é a presença da Dra. Taka Oguisso como uma de suas consultoras para a América Latina. A outra associação internacional, a qual filiou-se em 1955, foi o CICIAMS (Comitê Internacional Católico de Enfermeiros e Assistentes Médico-Sociais) que tem como um dos objetivos estimular em todos os países a criação e o desenvolvimento de associações profissionais católicas a fim de assegurar apoio moral e espiritual às enfermeiras. Estas tornaram-se importantes à medida que problemas apontados pela comissão da ABED, em 1947, como a falta de atrativos para a profissão, ausência de órgãos normativos e reguladores da enfermagem e a necessidade de ampliar e elevar o nivel de formação de profissionais habilitados podiam e podem ser analisados e discutidos. Antes do CICIAMS (em nivel internacional) outras associações católicas apareceram (em nivel nacional), sendo estas: a União das Religiosas Enfermeiras do Brasil (UREB) e União Católica de Enfermeiras do Brasil (UCEB).

Durante o V Congresso Nacional de Enfermagem, em 1951, merece destaque o ponto que trata da retirada da profissão de enfermeiro da categoria comercial na qual havia sido colocado pela Consolidação das Leis do Trabalho (CLT) em 1943 (título obtido em 1940 e retirado três anos mais tarde). Em 1955, a ABEn consegue que os enfermeiros sejam considerados como profissionais liberais, permanecendo assim até hoje.

A partir dai iniciou-se um novo processo de luta: fortalecer a profissão em seu caráter científico. Isso se daria através da pesquisa, o que, por sua vez, necessitaria da qualificação de profissionais através de cursos de pósgraduação. Os anais dos congressos, que se realizam a cada ano, possibilitamnos ver, em termos de quantidade e qualidade, o quanto a enfermagem está se voltando para a pesquisa, buscando sempre avaliar sua assistência, tornar evidentes as várias situações que interferem em sua ação e os novos meios de que se utiliza. A primeira pesquisa de enfermagem nos pais deu-se em 1956, cujo tema foi "Levantamento de Recursos Humanos e Necessidades de Enfermagem", realizada pela ABEn.

Com relação à Semana Brasileira de Enfermagem, inicialmente denominada de Semana da Enfermeira, passou em 1958 à nova denominação. Foi criada em 1940 e somente oficializada em 1960. É uma semana dedicada, essencialmente, à divulgação da enfermagem e de seu desenvolvimento atual. Tem início no dia 12 prosseguindo até 20 de maio.

O código de ética passou a ser incorporado pela ABEn no ano de 1958, sendo renovado em 1975. É considerado como sendo instrumento básico e necessário para definição dos papéis, deveres, responsabilidades e proibições na enfermagem.

Tem-se, em 1973, o término da construção da sede administrativa da ABEn e a criação do Conselho Federal de Enfermagem, constituindo-se em mais um luta conquistada. Sendo realizada a primeira reunião do COFEN em 1975, deliberou-se a instalação e organização dos Conselhos Regionais de Enfermagem(CORENs). 
Em 1976, foram comemorados os 50 anos da ABEn no XXVII CBEn, ocorrido no Rio de Janeiro e que teve como um dos temas principais a projeção da ABEn na comunidade brasileira. Neste mesmo ano novas reformas estruturais foram propostas pela $A B E n$, sendo uma de suas questões a inclusão do acadêmico de enfermagem na associação de classe como membro especial.

Já na década de 80 a ABEn criou elos com outros órgãos com o propósito de concentrar recursos para o desenvolvimento da profissão, sendo eles públicos (CNPq, MPAS, MS, CAPES, FINEP, Senado Federal e Câmara dos Deputados) e privados (Mocambo, UNICON, Becton Dicknson, Corcil, Prado Com.Ind.), promovendo ainda a venda de quadros e brindes. Tais recursos foram utilizados em prol das edições da REBEn e do Boletim Informativo e participação em encontros científicos. Outros laços foram firmados, sendo eles com a Organização Pan-americana de Saúde (OPAS), a qual financiou o $\mathrm{V}$ volume de "Informações sobre Pesquisas e Pesquisadores em Enfermagem", e também da Comissão de Especialistas em Ensino de Enfermagem com o Ministério de Educação, com o objetivo de aprimorar o ensino de enfermagem no Brasil.

A ABEn cresceu como associação e firmou-se perante a sociedade ao tomar posicionamento relacionado a problemas fundamentais da enfermagem: 1.Subsídios para uma política de saúde; 2 .Nova política para ensino superior de enfermagem; 3.Questões salariais. E vivenciou passo a passo a mudança para a Nova República, assegurando a conquista de maiores espaços para a profissão.

No CBEn de 1985 foi lançado o livro intitulado "Força do Trabalho de Enfermagem", considerado como pesquisa de maior abrangência relacionada à enfermagem, realizada conjuntamente pelo COFEn/ABEn.

Evidenciando a atuação da enfermagem na atenção primária de saúde, o ICN, a OMS e UNICEF solicitaram o apoio dos enfermeiros de todo o mundo para empreenderem esforços na campanha "imunização de todas as crianças do mundo até 1990", elaborando políticas de ação condizentes com as condições existentes em seus países de origem.

Em setembro de 1985, foi realizado o VIII Encontro Nacional de Pesquisa em Enfermagem, promovido pela ABEn-SP, que teve como principais objetivos avaliar e discutir os parâmetros de pesquisa em que se encontrava a enfermagem e quais as perspectivas futuras.

A VIII Conferência Nacional de Saúde, marco da saúde pública, ocorrida entre 17 e 21 de março de 1986, contou com a participação da ABEn e COFEN, que propuseram direitos relacionados à saúde e à assistência de enfermagem.

Outros marcos da história da ABEn constituem-se na $47^{\circ}$ Semana de Enfermagem e XXXVIII CBEn(1986), quando foram comemorados os 60 anos de luta ativa e participação da ABEn com o intuito de conquistar um espaço cada vez mais atuante para a profissão. Deu-se, ainda neste ano, a criação da "Comissão de estudos para reformulação de estatutos e regimento da ABEn", ocorrida na cidade de São Paulo, e que teve como responsabilidade discutir a 
assembléia extraordinária da delegação da ABEn. Iniciando-se o ano de 1987, a REBEn luta por um financiamento da revista pelo CNPq(Conselho Nacional de Pesquisa) e pela FINEP, sendo que parte considerável da mesma já era financiada por esta última.

A Revista Brasileira de Enfermagem, principal veículo de idéias científicas da comunidade, passa por muitas dificuldades, principalmente devido à conjuntura sócio-econômica do pais naquele ano. Esta, como veículo primordial de comunicação da Associação Brasileira de Enfermagem, teve que se preocupar com toda essa problemática para encarar de forma mais direta a situação pela qual passava naquele momento. Nessa época dava-se todo apoio aos enfermeiros e técnicos na luta pela democratização da sociedade brasileira e das instituições de saúde.

Ocorre a luta pela união da enfermagem em todos os niveis internos (enfermeiros ,técnicos, auxiliares e os não profissionalizados) por sentir-se a necessidade de buscar uma postura mais crítica e criadora. Nisso centrou-se uma das reflexões das instituições de saúde e das entidades de classes.

Iniciou-se, entre 1987 e 1988, a discussão junto à "Comissão de especialistas em enfermagem do MEC (Ministério da Educação e Cultura)" sobre reformulação do currículo de graduação e também o debate sobre as inter-relações da pósgraduação e a prática profissional.

As "Comissões de educação e de serviço de enfermagem" preocupavam-se com as pessoas não qualificadas exercendo funções na equipe de enfermagem. Necessitava-se de uma legislação atualizada que definisse papéis e funções do profissional e dos ocupacionais. Uma outra preocupação da $A B E n$ foram as mudanças $e$ as idéias que se formavam. A nova legislação do exercício profissional da enfermagem. entrou em vigor no Brasil no dia 08 de junho de 1987. Era a Lei $n^{\circ} 7498$, que seria mais tarde substituída pela Lei $n^{0} 2604$, de 1995.

Foram dez anos de esforço e luta da enfermagem brasileira para conseguir a atualização da legislação do exercício profissional. Fazendo uma análise mais precisa, denota-se que o resultado deste processo estava muito distante do desejado e que uma legislação adequada à enfermagem ainda era uma necessidade. A prática da enfermagem continuava sem nenhuma proteção legal, sendo que os seus profissionais estavam submetidos a uma sobrecarga emocional, física e técnica na execução de atividades. Com jornadas e salários inadequados, a categoria vivenciou uma crise. Naquele momento, a ABEn convidava todos para se engajar em uma jornada de reflexão, de luta e, a partir dai, alcançar novos dias para a profissão conseguindo, com isto, uma legislação mais adequada ao seu peso decisivo no atendimento das necessidades de saúde da população.

Combatendo $O$ falseamento ideológico e buscando $O$ respeito aos movimentos, a comunidade de enfermagem se desenvolveu. A ABEn sofreu o dilema de explicar o significado deste momento fazendo a exposição de seus princípios à critica e conctatando que a soberania era advinda da união da 
classe profissional de enfermagem. O momento político-social exigia explicitação de compromissos e a informação, buscando o reconhecimento das atividades exercidas pela profissão.

A principal luta da diretoria da ABEn, na gestão do ano de 87 , era para conseguir autonomia financeira para a REBEn, vindo a propor uma desvinculação dos órgãos financiadores e o encaminhamento de uma proposta de reorganização. A REBEn tinha como principal responsabilidade divulgar todos os possiveis trabalhos científicos produzidos pela categoria, principalmente pesquisas, que constituiam instrumento de qualificação da prática de enfermagem brasileira, assim como o Jornal Brasileiro de Enfermagem mantinha atualizadas as notícias acerca da profissão (com periodicidade bimestral, encontra-se no seu $20^{\circ}$ ano).

Ao iniciar o ano de 1988, ainda que atravessando uma crise sem precedentes na história, conseqüência de uma política econômica recessiva, em que reinavam os interesses dos grandes grupos financeiros nacionais, a $A B E n$ teve como desafio encontrar uma forma de resistência para superar a crise.

As características que mais marcaram a crise da profissão nessa época foram a instabilidade, a insegurança e a falta de confiança no futuro. A Lei do Exercício Profissional não abordava essas questões, preocupando-se somente com interesses curativos e empresariais, compondo, assim, a política de saúde dominante no Brasil. A Lei $n^{0} 7498$ trouxe pontos positivos como a participação efetiva da enfermagem nas decisões e gestão do setor de saúde, bem como o reconhecimento do técnico, a valorização dos trabalhadores de enfermagem e a conquista da qualificação de todos os atendentes de enfermagem através da suplência.profissionalizante, até o ano 2000.

A partir desta linha de raciocínio, precisou-se repensar a educação como espaço de conscientização da categoria e também como componente na formação de uma sociedade melhor. Assim, a associação tinha mais uma de suas lutas naquele ano de 1988. Partindo desse pensamento, o ensino de enfermagem absorveu a ideologia de que as políticas educacionais deveriam investir para que o enfermeiro fosse comprometido em ajudar as vítimas da sociedade.

O desafio foi incorporado pela $A B E n$, não de forma isolada mas como um trabalho coletivo contando com a participação das seções regionais da $A B E n$, dos cursos de enfermagem, de entidades oficiais, de todos os enfermeiros, na luta da construção de um projeto político para a enfermagem de maneira que ela se tornasse uma classe forte, autônoma e representativa. Esse projeto não seria somente a montagem de um novo currículo mínimo, novos programas, novas metodologias, mas sim, conhecer especificamente as finalidades educacionais, as estruturas da sociedade e compreender a divisão técnica e social do trabalho da enfermagem. A posição da coordenação de educação da ABEn, em 1988, era de que o ensino que interessava aos que suportaram a crise era aquele que se baseava no concreto e contribuía para transformação da realidade da saúde do país. 
Em um segundo momento em 1988, tivemos como ponto principal a pesquisa no campo da enfermagem. A ciência vista como algo mais do que abstração, fornecendo para as pessoas informações variadas sobre coisas vivas, valorizando o homem e o seu mundo. A pesquisa foi e continua sendo fundamental para a profissão, pois orienta sua ação e define sua ciência. Pelas suas características e complexidade, a enfermagem requer várias abordagens, tanto da pesquisa quantitativa como da qualitativa. E para evoluirmos em uma assistência de enfermagem aprimorada é necessário incorporar-se a uma teoria de pesquisa, que se desenvolva a partir das relações reais e concretas, guiadas sempre por uma investigação.

Face às eleições presidenciais de 1989, ano de muita esperança na perspectiva da construção da democracia brasileira, a enfermagem participou ativamente de todos os "momentos de luto e luta" vividos pela sociedade, explicando que esta é um trabalho coletivo que tem como principal finalidade a preservação e recuperação da saúde, que é um dos direitos entre outros que subsidiem o direito maior da cidadania. Neste contexto, a ABEn articulou-se nos niveis nacional e estadual e fez-se presente nos movimentos sociais gerais e no setor de saúde, buscando consolidar a enfermagem como co-participante dos processos que vêm ao encontro da garantia desse direito.

As dificuldades financeiras apresentadas pelas entidades de classes neste últimos anos foi somente um reflexo da conjuntura externa, fazendo com que houvesse um atraso na publicação da revista, além de exigir a concentração de alguns números em apenas um único volume. Nessa ocasião, a presidente da ABEn nacional falava da importância da manutenção da publicação da revista pelos seus associados, buscando desta maneira sua autonomia.

O governo federal, descumprindo o artigo 196 da Constituição, que define a saúde como "um bem de direito de todos e dever do Estado", diminui o quadro de pessoal das instituições de saúde e cancela a $9^{\text {a }}$ Conferência Nacional de Saúde (CNS) programada para março de 1990. Os profissionais de enfermagem foram, então, chamados a se organizarem e pressionarem o poder público para que a CNS fosse realizada para a garantia dos direitos constitucionais, mostrando a construção definitiva de um sistema único de saúde que satisfizesse os interesses dos brasileiros.

No $42^{\circ}$ CBEn, em 1990, a assembléia nacional de delegados determinou o direito do associado receber a REBEn independentemente da sua renda, possibilitando assim que profissionais da saúde ou interessados tivessem acesso à mesma, democratizando o saber em saúde e fortalecendo a enfermagem brasileira através da atualização e desenvolvimento tecnológico e científico da categoria, não esquecendo o lado político. As dificuldades financeiras da ABEn determinaram a perda desse direito do associado, tornando-se a REBEN uma revista com assinatura paga. 
A ética, a solidariedade, a defesa do direito comum ao expressar e lutar por suas idéias e propostas perfazem os princípios da gestão 1992/1995 da ABEn NACIONAL que propõe o fortalecimento da entidade e ampliação da interrelação enfermagem e comunidade geral.

Divulgando alternativas para a prática profissional e, da mesma forma, contribuindo para utilização da tecnologia desenvolvida por profissionais de enfermagem, no $44^{\circ} \mathrm{CEBEn}$ ocorreu a primeira "exposição tecnológica", sendo apresentados vários inventos, alguns já patenteados com grande aceitação de público e mercado.

Por ocasião do $45^{\circ}$ CEBEn, realizado em 1993, tomou corpo mais um processo de reformulação do estatuto da $A B E n$ que representa a base jurídica da entidade e organização da sociedade civil representativa da enfermagem. Nesse mesmo ano, a enfermagem comemora cinqüenta anos da existência da sua primeira escola no Ceará. Por iniciativa do CEPEN (Centro de Estudos e Pesquisa em Enfermagem), foi criado o prêmio para acadêmicos de enfermagem que concorressem com trababalho durante a realização de Semana Brasileira de Enfermagem. No periodo até 1995, foram promovidos, pela ABEn, cursos como - de nutrição parenteral, comunicação interpessoal em enfermagem, fenomenologia, atualização em enfermagem-nefrológica, metodologia de pesquisa, seminários como o SENPE (Seminário Nacional de Pesquisa em Enfermagem) sobre assistência ventilatória mecânica e algumas jornadas como a Norte/Nordeste de Enfermagem em Centro Cirúrgico e Centro de Material.

\section{ASPECTOS POLÍTICOS:}

- Filosofia da ABEn:

"Fundamentada na Constituição, sua filosofia enfatiza a valorização humana e sua promoção, seja ao nivel individual ou coletivo, reconhecendo que a enfermagem tem como objetivo central o homem em sua dignidade absoluta" 1.

- Finalidades da ABEn:

“I - Congregar os enfermeiros e técnicos de enfermagem e incentivar o espirito de união e solidariedade entre a categoria;

II - Promover o desenvolvimento técnico-científico e profissional dos integrantes da enfermagem no país;

III - Promover integração com as entidades representativas da enfermagem, na defesa dos interesses da profissão;

IV - Articular com outras entidades do setor e dos trabalhadores em geral mecanismos em defesa de uma política de saúde integral e igualitária para todo o povo brasileiro; 
$V$ - Representar a enfermagem nas decisões de interesse da profissão, especialmente no que diz respeito às questões de saúde e educação;

$\mathrm{VI}$ - Promover intercâmbio com as associações nacionais $e$ internacionais para o desenvolvimento profissional e cientifico dos associados;

VII - Instituir e manter obra filantrópica destinada à assistência dos associados idosos, desvalidos, ou necessitados de amparo;

VIII - Divulgar trabalhos e estudos de interesse da enfermagem, mantendo um órgão oficial de publicação periódica, promover, estimular a pesquisa e o desenvolvimento tecnológico da enfermagem;

XIX - Adotar medidas necessárias à defesa da profissão" ${ }^{2}$.

\section{MOMENTO ATUAL}

Atualmente a enfermagem encontra-se em pleno desenvolvimento. Impulsionada pela $A B E n / C O F E n$, a profissão conquista dia após dia um espaço maior e mais respeitado na sociedade. Estrutura-se com o COFEN (Conselho Federal de Enfermagem), os CORENs (Conselhos Regionais de Enfermagem) e a REBEn. A pesquisa tem sido uma constante, a concorrência do vestibular tem aumentado de forma significativa (quase 20 para uma vaga), o que demonstra que se está conseguindo passar a imagem de uma categoria que, através do esforço individual e coletivo, juntamente com as instituições e associações que a fazem, tem alcançado o reconhecimento da comunidade. A mudança de currículo já aconteceu, demonstrando uma atualização frente ao momento atual de saúde. A FNE (Federação Nacional dos Enfermeiros) e ABEN, associados ao SENECE (Sindicato dos Enfermeiros do Estado do Ceará) vêm travando uma luta incansável pela derrubada do veto presidencial ao $P L$ 29/95, que determina a jornada de 30 horas/semana para o exercício da profissão. Comemoramos, durante a execução desse trabalho, a $57^{\text {a }}$ Semana Brasileira de Enfermagem e a $12^{\text {a }}$ Convenção Interiorana de Enfermagem, nas quais enfermeiros e acadêmicos se reuniram para festejar todas as conquistas alcançadas, avaliar a evolução da profissão ao longo dos seus 70 anos e discutir sobre temas sóciopolítico-econômicos atuais que interferem de forma significativa na enfermagem. O currículo novo está em fase de implantação em todo o país. O SENECE encontra-se atuante no sentido de congregar a classe na busca pelos seus direitos, encontrando amplo apoio da ABEn - CE. 


\section{CONCLUSÃO}

Ressalte-se a extrema importância de relatar a história da Associação Brasileira de Enfermagem para que seja entendido todo seu processo histórico. Ao evidenciar as lutas e conquistas, ao descrever seus marcos, princípios, filosofia e caracterizá-la nos dias atuais, tem-se a oportunidade de aprofundar o saber acerca da Associação e perceber o quanto ela contribui para o desenvolvimento da profissão, seja através do aspecto técnico-científico ou do sócio-político-econômico. Considera-se que os objetivos propostos foram alcançados, pois a essência da ABEn transpareceu em cada parágrafo, desde a fundação ao momento atual, no qual comemoram-se os seus 70 anos. Nesta data, levanta-se a importância de nos associarmos, concentrando nossas forças de forma a nos tornarmos uma potência, mas para isto é necessário que tenhamos a percepção da união de classe, que falemos em uma só voz nossas reivindicações e que busquemos juntos um espaço cada vez maior de atuação do enfermeiro. Assim sendo, devemos nos reportar ao passado e verificar como e quanto lutaram nossas pioneiras, como defenderam acima de tudo e de todos esta profissão: Enfermagem. E como amaram $O$ seu trabalho $e$ suas companheiras e se uniram. Desta união surgiu a $A B E n$ e todos os outros: COFEN, CORENs, originou você, enfermeiro, e nós, acadêmicas de enfermagem, e dentro de nós existe uma vontade forte de buscar condições melhores para a profissão, para a sociedade, mas conscientes de que enfrentaremos sempre muitas lutas, no entanto com a certeza de que obteremos muitas conquistas porque defendemos uma causa nobre: A vida. 


\section{ANEXO I - (ENTREVISTA: NA SUA OPINIÃO, O QUE MAIS LHE MARCOU NOS ÚLTIMOS DEZ ANOS DA ABEn?)}

"Uma das coisas mais importantes que eu achei que aconteceu nesses últimos anos, foi a participação de mais estudantes nos congressos e como conseqüência uma maior produção científica, maior apresentação de trabalhos. Os cursos de pós-graduação, mestrado e doutorado, tanto dos professores, como os próprios alunos, têm participado e incentivado a pesquisa, sendo a sua divulgação feita pela associação".

"Vejo como o marco da ABEn-Ce nos últimos dez anos a realização do Congresso Internacional de Urgência, que proporcionou o aperfeiçoamento nesta área aos profissionais de enfermagem, como também a aquisição de sua sede própria".

"Considero que houve um aumento da produção científica em conseqüência da expansão dos cursos de pós-graduação, devido à ABEn estimular a divulgação destes trabalhos. A ABEn sempre estimulou de forma bem decisiva, a sua ligação com os sindicatos, sempre apoiando tudo que fosse relacionado à categoria. A ABEn é uma entidade vanguarda dentro da enfermagem. Sou expresidente da $A B E n$, e sei que quem faz a $A B E n$ e quem a mobiliza é a sua filosofia."

"A Entidade tem marcado posição nas discussões de temas importantes para a categoria como o exercício profissional e a legislação de ensino... A história da enfermagem confunde-se com a história da ABEn. A criação dos sindicatos, do COFEn e COREns tem sua origem na ABEn. A última experiência recente ocorreu em mandato de três anos que se encerrou em dezembro passado. Nesta oportunidade pede perceber a escassa participação dos enfermeiros na entidade, tanto como associados na entidade (apenas 10\% do quadro de enfermeiros do COREn-CE são associados da ABEn) como atuantes no processo ativo e decisório."

"O engajamento da ABEn nas lutas mais amplas da categoria. Anteriormente havia a percepção de que somente as questões relacionadas aos aspectos culturais e científicos eram de interesse da ABEn. Hoje ela está ao lado do sindicato e tem buscado apoiar as demandas quanto às políticas de saúde, participação da sociedade, busca da consciência de cidadania, etc." 
"A mudança de postura dos dirigentes da ABEn-nacional, a partir do "movimento participação", introduzindo o envolvimento político para a categoria de enfermeiros, mas que, com a radicalização de suas idéias, acabou afastando um expressivo número de profissionais. Houve também incentivo de alguns dirigentes de seções para a participação ef etiva de estudantes da graduação nas atividades da ABEn. Faz-se necessário um novo tempo na ABEn, livre de perseguições políticas, voltado para a credibilidade da profissão, independente de raça ou credo."

"Considero como "marco" dentro da enfermagem, que tem por seu orgão divulgador a REBEn, através da ABEn, que houve um avanço considerável com as entidades de classe, como COFEN-CORENs e os sindicatos e Confederação Nacional dos Enfermeiros. Mas considero que o nivel de politização dos enfermeiros no seu todo é "precário" para haver uma fortificação geral da associação e dos sindicatos."

“ Maior preocupação no desenvolvimento da pesquisa em enfermagem...Conquista de espaço de trabalho... Crescimento da questão do associativismo...Maior participação nos projetos politicos do país...Uma postura mais ousada nas lutas da categoria...O crescimento dos congressos nacionais como instrumento de socialização do saber da enfermagem... Descentralização através das convenções interioranas das questões científicas e experiências de profissionais das cidades do interior..." 


\section{ANEXO II - QUADRO SÍNTESE}

Retratar, de maneira resumida, o caminho percorrido até a fundação da ABEn e REBEN.

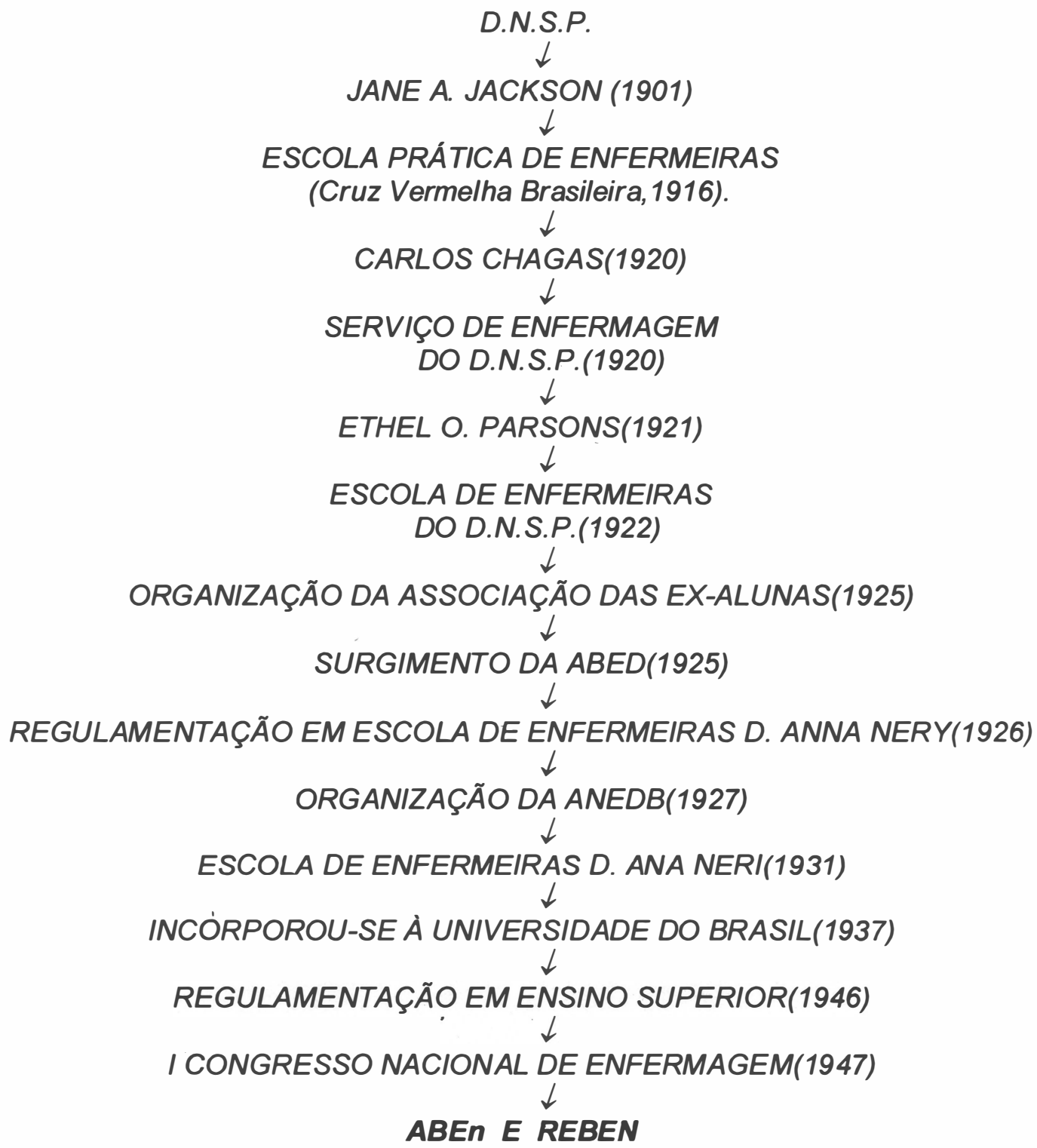




\section{ANEXO III - TÍTULOS DOS PRÊMIOS NO CBEN}

- "Luís Neto dos Reis"- característica: "contribuição relevante sobre atividade da prática profissional ef etivamente realizada e que representa um expansão do papel do enfermeiro."

- "Wanda Horta"- característica: "trabalho mais significativo no campo de prática de enfermagem."

- "Ariadne Lopes de Menezes"- característica: "trabalho de singular valor, sobre Prevenção e Controle de Infecção Hospitalar."

- "Isaura Barbosa Lima"- característica: "melhor trabalho na área de Enfermagem em Saúde Pública."

- "Zaíra Cintra Vidal"- característica: "trabalho que comunique inventos, descobertas, ou adaptações significativas da prática de enfermagem".

- "Edith Magalhães Fraenkel"- característica: trabalho sobre Pesquisa Científica em Enfermagem".

- "Glete de Alcântara"- característica: "melhor trabalho de estudantes do curso de graduação sobre o tema da Semana de Enfermagem".

- "Marina de Andrade Rezende"- característica: "melhor trabalho escrito por alunos de graduação". 


\section{REFERÊNCIAS BIBLIOGRÁFICAS}

1. ABEn. Estatuto da Associação Brasileira de Enfermagem, Fortaleza, 31p.

2. CARVALHO, Anayde Correa de. 50 anos da ABEn. Associação Brasileira de Enfermagem,Brasília: 1976, 50 p.

3. Informativo $A B E N_{1}$ Natal, n. 2, out, 1990, 4p.

4. . Fortaleza, n. 1, nov./dez., 1992, 5p.

5. .n. 1, jan./fev.,1993, 5p.

6. .n. 3, set./nov.,1995,2p.

7. .n. 1, jan./fev.,1996,2p.

8. NASCIMENTO, Kátia Andrea Fernandes. 60 Anos da ABEn. Associação Brasileira de Enfermagem, Fortaleza, 1986, 26p.

9. REVISTA BRASILEIRA DE ENFERMAGEM, Brasília, n. 2 e 3, jan/fev.,1987, v. 40, 1-81p.

10. .n. 4, abr/set., 1987, v. 40, 89-180p.

11. .n. 1 , out./nov., 1987, v. 40, 183-262p.

12. .n. 1, jan./mar., 1988, v. 41, 5-86p.

13. .n. 2, abr./jun., 1988, v. 41, 87-172p.

14. .n. 1,2,3 e 4, jan./dez., 1989, v. 42, 1-50p.

15. .n. 1,2,3 e 4,jan./dez., 1990, v. 43, 1-48p.

16. .n. 1, jan./mar., 1992, v. 45, 1-91p.

17. .n. 4 , out./dez., 1992, v. 45,. 243-324p

18. .n. 1, jan./mar., 1993, v. 46,. 1-88p.

19. .n. 2, abr./jun., 1994, v. 47, 85-212p.

20. .n. 3, jul./set., 1994, v. 47, 213-328p.

21. .n. 4, out./dez., 1994, v. 47, 329-452p. 